\title{
Influence of Redox on Manganese Geochemistry across a Rainfall Gradient in Hawaii
}

\author{
MengQiang ZhU ${ }^{1}, \mathrm{Ke} \mathrm{Wen}^{1}$, Oliver A. Chadwick ${ }^{2}$ \\ AND ZHUOJUN ZHANG ${ }^{1}$ \\ ${ }^{1}$ Department of Ecosystem Science and Management, \\ University of Wyoming, Laramie, WY 82071 \\ ${ }^{2}$ Department of Geography, University of California, Santa \\ Barbara, California 93106, United States
}

Manganese (Mn) is ubiquitous in water, soils and sediments and exists as $\mathrm{Mn}(\mathrm{II}), \mathrm{Mn}(\mathrm{III})$ and $\mathrm{Mn}(\mathrm{IV})$. The redox conditions of the environment control the distribution of the three Mn oxidation states, accordingly $\mathrm{Mn}$ bioavailability, type and amount of $\mathrm{Mn}$ oxides/oxyhydroxides, and their geochemical reactivity. Climate is a major factor influencing soil redox conditions, but it remains unclear how climate affects the Mn oxidation state composition via controlling the redox conditions. In this study, the Mn oxidation state compositions in soils were characterized along the Maui rainfall gradient in Hawaii with the mean annual precipitation (MAP) of $1.5-5 \mathrm{~m}$, using Mn K-edge XANES spectroscopy. The rainfall gradient resulted in a wide range of soil redox potential $(451 \mathrm{mV}--60 \mathrm{mV})$, and the redox conditions shift from oxic to suboxic and to anoxic with increasing MAP. Results showed that $\mathrm{Mn}(\mathrm{IV})$ decreased and $\mathrm{Mn}(\mathrm{II})$ increased in relative abundance in surface soils with increasing MAP because the soils became increasingly reducing. The Mn(III) increased and then decreased with increasing MAP due to the one-electron-two-step reduction of $\mathrm{Mn}(\mathrm{IV})$ to $\mathrm{Mn}(\mathrm{II})$, and its fraction reached a maximum 55\% at 2.75 $\mathrm{m}$ MAP. The increasing reduction of $\mathrm{Mn}(\mathrm{IV})$ to $\mathrm{Mn}$ (II), along with intensifying leaching, resulted in the loss of total soil Mn with increasing MAP. Moreover, at each rainfall site, the total soil $\mathrm{Mn}$ was preferentially accumulated in the subsurface; due to increasingly oxidizing conditions, $\mathrm{Mn}(\mathrm{IV})$ increased and $\mathrm{Mn}(\mathrm{II})$ decreased while $\mathrm{Mn}$ (III) often shows a maximum in the subsurface with increasing soil depth. This study indicates that $\mathrm{Mn}(\mathrm{III})$ could be the major solid Mn species in soils, which has been overlooked in literature. The weak Mn redox cycling and the absence of $\mathrm{Mn}$ (IV) oxides at high rainfall suggest the capability of $\mathrm{Mn}$, particularly in surface soils, is limited to accelerate SOM decomposition, oxidize redox-active compounds and scavenge other trace metals. 